\title{
Match-mismatch dynamics and the relationship between ocean-entry timing and relative ocean recoveries of Central Valley fall run Chinook salmon
}

\author{
William H. Satterthwaite ${ }^{1,2, *}$, Stephanie M. Carlson ${ }^{3}$, Shanae D. Allen-Moran ${ }^{1}$, \\ Simone Vincenzi ${ }^{2}$, Steven J. Bograd ${ }^{4}$, Brian K. Wells ${ }^{1}$
}

${ }^{1}$ Fisheries Ecology Division, Southwest Fisheries Science Center, National Marine Fisheries Service, NOAA, 110 Shaffer Rd, Santa Cruz, CA 95060, USA

${ }^{2}$ Center for Stock Assessment Research, Applied Math and Statistics, University of California, Santa Cruz, CA 95064, USA

${ }^{3}$ Department of Environmental Science, Policy, and Management, University of California Berkeley, 130 Mulford Hall \#3114, Berkeley, CA 94720, USA

${ }^{4}$ Environmental Research Division, Southwest Fisheries Science Center, NOAA, Pacific Grove, CA 93950, USA

\begin{abstract}
The match-mismatch hypothesis suggests there is an optimal window for organisms to undergo key life cycle events. Here, we test the importance of match-mismatch dynamics in the timing of salmon arrival to the ocean, relative to ecosystem phenology, for the ocean survival rates of hatchery-origin fall run Chinook salmon originating from California's Central Valley. Specifically, we considered tag recovery data for releases of coded-wire tagged fish released into the San Francisco Estuary during the years 1978 to 2010. We determined a time lag for each release relative to the local spring transition date (initiation of net upwelling). Additionally, we obtained information on fish condition and size at release, the number of fish released corresponding to distinct tag codes, and yearly stock-specific harvest rate estimates. We used generalized linear models, generalized additive models, and cross-validation to identify the best-supported models for the effects of release timing and other covariates on age-3 ocean fishery recovery rates, a proxy of ocean survival rates. Release time is a useful predictor of within-year variation in survival rates, above and beyond the effects of size at release, presence of disease, and the use of net pens, and the lag relative to spring transition was a slightly better predictor than year-day. The optimal release timing appeared to occur around the end of May, and the optimal time lag appeared to be approximately 70 to $115 \mathrm{~d}$ after the spring transition date. However, timing is only one of many factors that affected within- and among-year variation in survival.
\end{abstract}

KEY WORDS: Timing $\cdot$ Mismatch $\cdot$ Recruitment $\cdot$ Phenology $\cdot$ Salmon $\cdot$ Survival $\cdot$ Fishery $\cdot$ GAM

\section{INTRODUCTION}

It has been long recognized that the environment plays a significant role in the variability of fish production. Specifically, when exposed to a poor environment at a critical time, the mortality rate of a population will be great, and ultimately, recruitment will be low (Hjort 1914, Cushing 1990). While these may be tenets in the fishery literature, most fisheries management is still based on information gleaned only from the population dynamics of the fish (Beverton \& Holt 1957) without an explicit consideration of environmental drivers. In the last few decades, however, environmental data series have been widely available to explore the impact of the environment on stock dynamics (Quinn \& Deriso 1999, Deriso et al. 
2008) and have been at times incorporated into management (Jacobson \& MacCall 1995, Logerwell et al. 2003). One recurring challenge in incorporating environmental variables into fisheries management models is that correlations between environmental drivers and fishery dynamics have a tendency to break down over time (Myers 1998). Focusing on explicit mechanistic hypotheses for the relationship between environment and fishery dynamics may increase the ability of environmental covariates to improve our understanding of fish population dynamics and management based upon these dynamics.

Here, we examine the relationship between the phenology of upwelling and the survival of juvenile salmon. The timing of ocean entry is a key life history trait that can profoundly influence the early marine survival of anadromous salmon (Bilton et al. 1982, 1984, Whitman 1987, Quinn 2005, Scheuerell et al. 2009). For example, Scheuerell et al. (2009) reported that Columbia River Chinook salmon and steelhead migrating to the ocean early in the season (early to mid-May) experienced 4- to 50-fold higher survival than individuals migrating late in the season (midJune). They also noted, however, that the timing of peak survival varied among years and hypothesized that the cause was interannual variation in nearshore conditions - especially variation in physical conditions and trophic dynamics. The natural spread in the timing of ocean entry ensures some degree of match between salmon arrival to the ocean and the timing of favorable ocean conditions but also some degree of mismatch (i.e. match-mismatch hypothesis sensu Cushing 1990). Indeed, this natural variation in the timing of ocean entry among and within stocks can be thought of as a bet-hedging strategy that spreads risk of mortality among individuals arriving at different times and thus minimizes the possibility of a complete mismatch between salmon arrival to the ocean and the availability of their prey.

Anthropogenic activities that influence the ocean arrival timing of salmon might then have large consequences for the survival of salmon populations. Such influences might include altered migration timing due to slowed passage around dams (e.g. Raymond 1979, 1988), altered river flows and temperatures from water management (Zabel \& Williams 2002, Williams 2008, Petrosky \& Schaller 2010), or changes to hatchery release strategies (Rechisky et al. 2012). Another management activity that directly affects salmon ocean arrival timing is barging (e.g. on the Columbia River; Budy et al. 2002) or trucking of the fish from the hatchery for direct release into the estuary (e.g. the California
Central Valley; California Hatchery Scientific Review Group 2012).

Chinook salmon originating from the California Central Valley have shown great variability in abundance in recent years, and mismatch dynamics have been invoked as among the potential explanations for this pattern (Lindley et al. 2009, Woodson et al. 2013). For example, juvenile salmon entering the ocean in 2000 and 2001 produced 2 of the greatest recruitment events on record, while only 5 yr later, early survival was so low that the stock collapsed to record low numbers, leading to an unprecedented emergency closure of commercial and recreational salmon fishing off the coasts of California and southern Oregon (Lindley et al. 2009). The proximate cause identified for this collapse, and likely a major contributor to variation over the longer term, is upwelling dynamics, including strength, duration, and timing (Barth et al. 2007, Lindley et al. 2009, Woodson et al. 2013). Previous work in this system has revealed that upwelling intensity relates to variability in a number of salmon vital rates, including growth (Wells et al. 2007, 2008) and recruitment (Logerwell et al. 2003, Wells et al. 2012, Burke et al. 2013). Here, we focus on the role of variability in the match between the timing of upwelling initiation and the time that emigrating juveniles enter the ocean. Upwelling strength and timing are indirectly and directly related to forage and predator dynamics in central coastal California (Croll et al. 2005, Wells et al. 2008, 2012, Thompson et al. 2012, Woodson et al. 2013). Increased nutrients associated with the initiation of the upwelling season positively correlate to zooplankton prey abundance in the Monterey Bay months later (Croll et al. 2005). Wells et al. (2008) and Thompson et al. (2012) demonstrate that, in addition to the indirect positive effect of providing nutrients for primary production, upwelling has a positive and direct effect on zooplankton and forage fish abundance in central California. The direct relationship is partly a result of physical forcing and advective properties associated with the interaction of wind strength and geographic features, such as Point Reyes, which provide an upwelling shadow in which a forage community can develop and be retained (Graham \& Largier 1997, Wing et al. 1998, Santora et al. 2012, in press). Juvenile salmon diet composition, condition, and abundance respond positively to the increased prey associated with upwelling (Thompson et al. 2012, Wells et al. 2012), and when prey is delayed or absent from the region, significant increases in mortality of juvenile salmon have been documented (Lindley et al. 2009, Woodson et al. 2013). 
A better understanding of how ocean entry timing affects marine survival is important for informed management of salmon stocks and in particular for managing anthropogenic activities that determine ocean entry timing and its influence on fish survival. Our goal is to examine linkages between hatchery release timing, environmental variability including upwelling linked to food web dynamics, and performance of the Central Valley Chinook salmon stock complex.

To quantify match-mismatch dynamics in this system, we compare the distribution of release dates to the spring transition date. We hypothesize that the phenology of upwelling in this system influences salmon survival by determining the availability of salmon prey in the coastal ocean (Croll et al. 2005). We test this hypothesis by examining success of hatchery-released salmon from the Central Valley with respect to release timing. Furthermore, considering the $30 \mathrm{yr}$ period, we ask if there is an optimal time lag between the timing of release and the spring transition date that maximizes the early marine survival of juvenile salmon. While numerous other factors undoubtedly affect salmon survival, and different factors will moderate the effects of timing on survival differentially across years, our primary question is whether the effect of timing is strong and consistent enough that a clear signal emerges, on average, even in the presence of numerous confounding factors. Given the demonstrated importance of upwelling in this system, we further ask whether the initiation of upwelling, as measured by the spring transition date, captures enough information about important ecosystem drivers and phenology that models measuring time relative to the spring transition date can better explain variability in the data than models based on calendar date alone.

\section{MATERIALS AND METHODS}

To examine how marine survival and recruitment to the fishery are affected by release timing and lags relative to ocean phenology as characterized by the timing of initiation of upwelling, we considered ocean recovery rates of individual release groups, identified by unique coded-wire tags (CWT; Johnson 1990, Lapi et al. 1990, Nandor et al. 2010). CWT are small pieces of wire injected into the snouts of juvenile salmon, and each tag is etched with a unique batch-code that identifies all individuals released in a given group (hereafter 'release group'). The Regio- nal Mark Identification System (RMIS, www.rmpc. org) is an online repository for CWT release and recovery data for the Pacific coast. Associated with each CWT in the RMIS database are descriptors such as the release date(s), total number of marked fish that were released, average weight of fish at release, developmental stage of fish at release, source hatchery, location of release, and a comments field that includes various notes including, for example, whether fish in a release group showed signs of disease or poor condition.

\section{Release groups identified by coded-wire tags}

We analyzed CWT groups released directly into San Francisco Bay for which the approximate time of ocean entry is known and results are not influenced by variability in survival during downstream migration. We queried the RMIS for all releases of CWT Central Valley fall run Chinook salmon released into the San Francisco Estuary through 2010. Note that all of these fish were of hatchery origin.

\section{Ocean recovery rates}

We also queried RMIS for all recoveries of CWT fish in the ocean recreational or troll fisheries reported by California Department of Fish and Game (CDFG; now the California Department of Fish and Wildlife [CDFW]) or the Oregon Department of Fish and Wildlife (ODFW) and calculated ocean recoveries $O_{i, a}$ as the sum of the 'estimated number' (i.e. expanded for subsampling of the harvest) reported for each recovery of an age a fish from the release group $i$ in the ocean fishery, repeated over all ageyear combinations subject to the fishery. To recover the tags, adults are sampled from commercial and sport fisheries. A known fraction, typically $\sim 20 \%$, of the harvest is examined for the presence of CWT. This allows calculation of a sample expansion factor that estimates how many CWT fish from a particular release group were likely in the total sampling stratum for each CWT read. Thus, for every CWT from a particular release group recovered in a particular sampling stratum with sample rate $f$, it is assumed that $1 / f$ fish were caught. We then use the sum of these $1 / f$ values across strata to estimate total recoveries. Ages are calculated as the difference between recovery year and brood year, where brood year is the year of spawning and fish are typically released the next calendar year. 


\section{Covariates and confounding issues}

Our direct interest is in the relationship between release timing and survival as indicated by ocean recovery rates. We characterized years on the basis of spring transition (Schwing et al. 2006, Bograd et al. 2009) at $39^{\circ} \mathrm{N}, 125^{\circ} \mathrm{W}$. Spring transition is defined as the day in each calendar year that the cumulative coastal upwelling index (for that year, integrated daily values starting January 1) first starts increasing from its minimum value, and this transition day is highly variable across years (Fig. 1). We hypothesized that 'time lag', the difference between the yearday (i.e. day of year) of release and the spring transition date, would provide a better predictor of relative survival than year-day alone.

We excluded individual release groups whose release dates spanned $>30 \mathrm{~d}$ since no single release date could be assigned to such groups (amounting to only $\sim 6 \%$ of all records). For the remaining groups, we determined the total number of marked fish in each release group $N_{i}$ released on year-day $t$ of year $y$. When a release group was released over multiple days, we characterized the group based on the midpoint of the release dates.

Our analyses also allowed for expected effects of numerous covariates, such as the use of acclimation (net) pens prior to release, and notes of disease or poor condition associated with individual release groups. Many studies (Ward et al. 1989, McGurk 1996) have found an effect of size at emigration on survival (but see Tomaro et al. 2012), so we included weight as a covariate as well. We removed data for release groups with no weight information ( $2 \%$ of records).

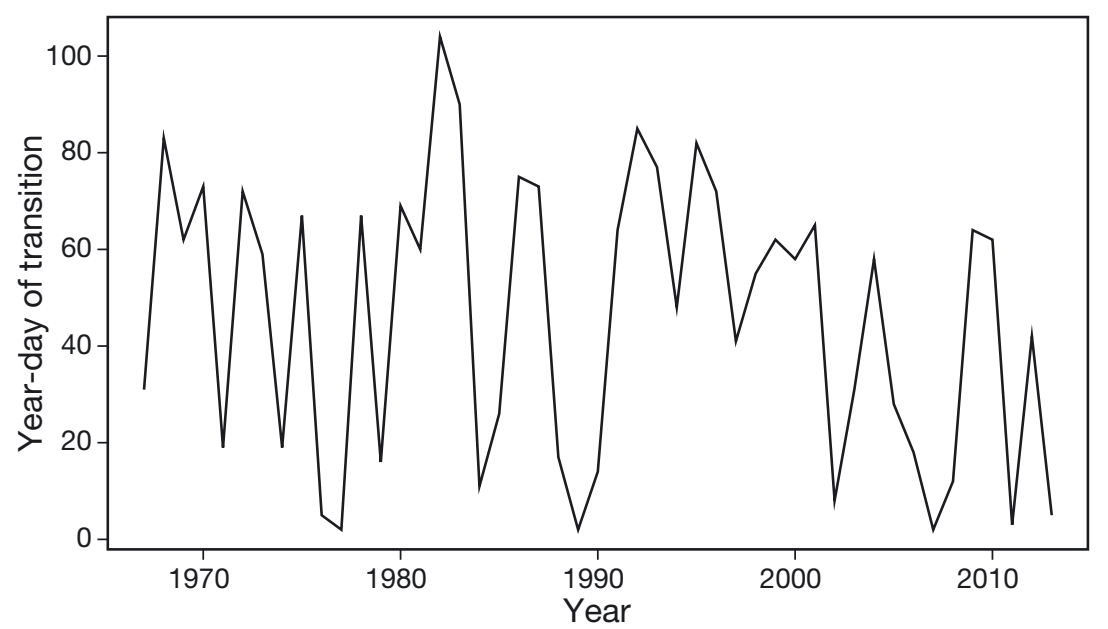

Fig. 1. Annual variation in spring transition date measured at $39^{\circ} \mathrm{N}, 125^{\circ} \mathrm{W}$ (see 'Materials and methods: Covariates and confounding issues' for methodological details); 'year-day' = day of year
Because release times varied among hatcheries, and some hatcheries had a very restricted range of release dates, we restricted our analysis to Feather River Hatchery releases, which released fish over a protracted period (see Supplement 1 at www.int-res. com/articles/suppl/m511p237_supp.pdf for further details). To reduce the collinearity between weight and release timing, we restricted our analysis to fish released as 'fingerlings' or 'advanced fingerlings' which make up the majority of releases $(\sim 90 \%)$, rather than the much larger smolts or much smaller fry. We considered only age 3 ocean recoveries because prior to being caught at age 3 , the predominant source of mortality is from natural causes, and recoveries of age 2 and age 4 fish are comparatively rare (Supplement 1 ; age 3 recoveries typically an order of magnitude higher than age 2 and age 4 , with negligible recoveries of other ages). We excluded releases from years 2006 and 2007 due to closures of the fishery in 2008 and 2009, precluding recovery of age 3 fish. Data filtering is described more fully in Supplement 1.

We also integrated into our analysis an approximation of Sacramento River fall run Chinook (SRFC) adult harvest rate based on the Sacramento Index (see 'Modeling recoveries' below) (O'Farrell et al. 2013). SRFC harvest rates were applied to recovery years of age 3 fish. Yearly estimates of SRFC harvest rates do not exist prior to 1983, limiting data to fish released after 1980.

Finally, one observation was excluded in which the year-day of release was far greater than other release groups. In total, we used information from 164 Feather River Hatchery release groups that were released in years 1981 to 2010 (Table 1).

\section{Modeling recoveries}

The expected number of age a ocean recoveries of release group $i$ $\left(O_{i, a}\right)$ is a product of the probability of surviving until being caught in ocean fisheries $\left(s_{i, a}\right)$, the conditional probability of a live fish being caught at age $a$ after being released in year $y\left(c_{y, a}\right.$ accounting for fishery effects in year $(y-1)+a)$, and the number released $\left(N_{i}\right)$. We assume the conditional probability of being caught at age 3 is proportional to the SRFC harvest rate $\left(c_{Y, 3}=\phi h_{Y}\right)$, where $\phi$ is a constant of 
Table 1. Annual number of release-groups released directly into San Francisco Bay by each California Central Valley fall Chinook hatchery (CM: Coleman; MC: Merced; MK: Mokelumne; NB: Nimbus; TC: Tehema-Colusa; FE: Feather). Releases spanning $>30 \mathrm{~d}$ were excluded, as were releases without information on release weight or those that reached age 3 in years before the Sacramento River fall run Chinook (SRFC) harvest rates were estimated. Only fingerling (finger.) and advanced fingerling (adv. finger.) releases from Feather River Hatchery were included in the models presented in this study (see Supplement 1 at www.int-res.com/articles/suppl/m511p237_supp.pdf)

\begin{tabular}{|c|c|c|c|c|c|c|c|}
\hline $\begin{array}{l}\text { Re- } \\
\text { lease } \\
\text { year }\end{array}$ & $\mathrm{CM}$ & $\mathrm{MC}$ & MK & NB & $\mathrm{TC}$ & $\begin{array}{l}\text { FE } \\
\text { All }\end{array}$ & $\begin{array}{c}\text { FE } \\
\text { (finger. and } \\
\text { adv. finger. } \\
\text { only) }\end{array}$ \\
\hline 1981 & 2 & 0 & 1 & 0 & 0 & 6 & 5 \\
\hline 1982 & 3 & 0 & 1 & 0 & 0 & 6 & 5 \\
\hline 1983 & 0 & 1 & 1 & 3 & 0 & 7 & 5 \\
\hline 1984 & 0 & 1 & 0 & 3 & 0 & 3 & 3 \\
\hline 1985 & 0 & 1 & 3 & 2 & 0 & 9 & 9 \\
\hline 1986 & 0 & 0 & 2 & 2 & 2 & 4 & 4 \\
\hline 1987 & 0 & 0 & 0 & 2 & 0 & 2 & 2 \\
\hline 1988 & 1 & 0 & 0 & 3 & 0 & 2 & 2 \\
\hline 1989 & 1 & 0 & 2 & 4 & 0 & 2 & 2 \\
\hline 1990 & 1 & 0 & 0 & 4 & 0 & 0 & 0 \\
\hline 1991 & 1 & 0 & 0 & 0 & 0 & 0 & 0 \\
\hline 1992 & 1 & 0 & 0 & 0 & 0 & 0 & 0 \\
\hline 1993 & 0 & 0 & 0 & 0 & 0 & 2 & 2 \\
\hline 1994 & 0 & 0 & 0 & 0 & 0 & 9 & 9 \\
\hline 1995 & 0 & 0 & 0 & 0 & 0 & 10 & 10 \\
\hline 1996 & 0 & 0 & 2 & 0 & 0 & 9 & 9 \\
\hline 1997 & 0 & 0 & 1 & 0 & 0 & 6 & 6 \\
\hline 1998 & 0 & 0 & 2 & 0 & 0 & 2 & 2 \\
\hline 1999 & 0 & 0 & 1 & 0 & 0 & 11 & 11 \\
\hline 2000 & 0 & 0 & 2 & 0 & 0 & 6 & 5 \\
\hline 2001 & 0 & 0 & 2 & 6 & 0 & 10 & 9 \\
\hline 2002 & 0 & 0 & 0 & 3 & 0 & 7 & 7 \\
\hline 2003 & 0 & 0 & 0 & 0 & 0 & 10 & 10 \\
\hline 2004 & 0 & 0 & 0 & 0 & 0 & 5 & 5 \\
\hline 2005 & 0 & 0 & 0 & 0 & 0 & 11 & 11 \\
\hline 2006 & 0 & 0 & 0 & 0 & 0 & 22 & 22 \\
\hline 2007 & 0 & 0 & 1 & 4 & 0 & 17 & 17 \\
\hline 2008 & 1 & 0 & 5 & 3 & 0 & 13 & 13 \\
\hline 2009 & 2 & 0 & 0 & 4 & 0 & 8 & 7 \\
\hline 2010 & 2 & 0 & 0 & 2 & 0 & 12 & 12 \\
\hline
\end{tabular}

the complex forces and interactions acting on ocean survival, there is likely to be much unexplained variation. For these reasons, we allow the variance $\left(\sigma^{2}\right)$ of the Poisson to be greater than the mean $(\mu)$ (Ver Hoef \& Boveng 2007). The variance of the related overdispersed Poisson distribution is calculated as follows:

$$
\sigma^{2}=\theta \mu
$$

such that $\theta$ is an estimated overdispersion parameter $(\theta>1)$.

Age 3 ocean recoveries (count data) are then modeled as an overdispersed (quasi) Poisson regression with mean $\mu$. We chose to use a quasi-Poisson distribution to allow for overdispersion rather than a negative binomial distribution due to its better computational performance and the lack of specific motivation for using a negative binomial. Our data do not allow separate estimation of $\phi$ and $s$; thus, we assume constant $\phi$ and interpret their product (which is itself modeled as a function of various covariates) as a measure of relative survival. Thus, the expected number of fish recovered $(\mu)$ from an initial release of $N$ fish is $s \phi h N$, yielding the following relation:

$$
\log (\mu)=\log (N h)+\log (\phi s)
$$

In the null model, no covariates other than year affect survival, resulting in the following relation:

$$
\log (\mu)=\log (N h)+\gamma_{y}
$$

proportionality, and the yearly SRFC harvest rate $\left(h_{y}\right)$ is the estimated number of age 3 to age 5 SRFC caught as a proportion of an index of yearly abundance (O'Farrell et al. 2013). If we further assume the fates of fish are independent, ocean recoveries of age 3 fish from $N_{i}$ number of tagged releases are binomially distributed:

$$
O_{i, 3} \sim \operatorname{Bin}\left(N_{i}, s_{i, 3} \phi h_{Y}\right)
$$

Since the unconditional probability of being caught $(s \phi h)$ is small, the number of recoveries can be well approximated by a Poisson distribution (Raff 1956). However, due to the non-independent fates of individual fish, the presence of measurement error, and where $\gamma_{y}$ is the combined effect of release year $y$ to recovery year $y+2$, and $\log (N h)$ is treated as a model offset. Year effects $\left(\gamma_{y}\right)$ are modeled as random effects and include unaccounted effects of natural mortality prior to being caught, exploitation and maturation of age 2 fish, ignored interacting effects between release timing and year, and temporal deviations in the proportional difference (otherwise assumed constant at $\phi$ ) between conditional recovery probabilities and the SRFC harvest rate.

Additional models are based on the null model and include a linear effect of release weight $\left(\beta_{1} W\right)$, an additive effect of net pens $\left(\beta_{n}\right)$, and/or an effect of disease/poor condition $\left(\beta_{\mathrm{d}}\right)$. Also, 2 other suites of 
models include either an effect of year-day of release or an effect of time lag relative to spring transition date. Without the effects of weight, disease, or net pens, the mean of a model that includes the effect of time lag (i.e. year-day of release $[t]$ - year-day of spring transition $[\tau]$ ) is generalized as follows:

$$
\log (\mu)=\log (N h)+f(t-\tau, v)+\gamma_{Y}
$$

$f()$ is a smooth function of a generalized additive model (GAM; Wood 2011) allowing for nonlinear effects of release timing on survival with a maximum of $v$ degrees of freedom, where $v$ ranges from 1 to 5 or is unspecified (i.e. unconstrained), and the maximum possible number of knots is $v+1$. This results in a total of 104 models, 8 with no release timing effects, 48 with potentially nonlinear effects of year-day of release, and 48 with similar effects of time lag.

One assumption of these models is that different release groups from the same year are equally vulnerable to fisheries (and thus that release timing does not have major effects on ocean distribution or sizeat-age, affecting the proportion of fish reaching legal size). Similar ocean distributions might be expected for similar run types originating from the same or adjacent watersheds, based on the results of Weitkamp \& Neely (2002) and Satterthwaite et al. (2014). Previous work (Hankin 1990) has suggested that later releases may be smaller than earlier releases in subsequent years (since later releases have spent less time growing in the more favorable ocean environment) but also found that later releases more often exhibit delayed maturation. Another assumption is an equal effect of release timing across years. For interpretability, we did not consider an interaction between release time and year (aside from that implied by changing the measure of release time to the lag from the spring transition date, which varies by year), but in Fig. 2, we present the relationship between release time and recovery rates standardized by SRFC harvest rates for individual years without a formal analysis.

Models were fit using the mgcv package (Wood 2011) in R 2.15.1 (R Development Core Team 2012).

We used Monte Carlo cross-validation rather than Akaike's information criterion due to concerns about non-independence of different release groups and a tendency for Akaike's criterion to favor overparameterized models (Shao 1993). The Monte Carlo crossvalidation method involves randomly splitting the data into $k$ subsets and calculating the prediction error for each subset. This is repeated over a number of iterations. We performed 1500 Monte Carlo cross validation iterations, each time randomly selecting
41 subsets ( $k$ ) with 4 data points per subset. Then, for each subset, we quantified the error when predicting a single subset (4 data points) from a model fitted to the remaining 40 subsets. The median number of releases per brood year is 6 ; thus, $k=41$ mostly ensures that if data from a particular release year are included in the validation subset, they are also included in the training data. Model errors for a validation subset were not calculated if release years in the validation subset were not included in the training data. Our model selection criterion is the minimum root weighted mean squared prediction error (RWMSE). Since release groups varied in size and thus in the certainty with which recovery proportions could be estimated, we weighted each datum on the basis of the number of total fish present in the corresponding initial release. We also consider a cross validation metric similar to $R^{2}$, denoted $R_{C V}^{2}$ (equivalent to OCV* in Rupp et al. 2012). Diagnostic plots for the best-supported model are presented in Supplement 2 at www.int-res.com/articles/suppl/m511 p237_supp.pdf.

\section{RESULTS}

Combining data from a wide range of release years (1981 to 2010) for Feather River Hatchery releases, the relationship between release timing and age 3 ocean recovery rates standardized by SRFC harvest rates appeared to vary across years (Fig. 2). This illustrates that, given current practices and covariation among factors, there is no consistent optimal release time that applies for all years, with 'optimal' defined as yielding the greatest availability to the fishery.

The best-supported model when applied to releases from Feather River Hatchery included the effects of net pen, disease, and release time as measured by time lag rather than year-day. This model had a mean RWMSE of 0.0037 and a mean $R_{C V}^{2}$ of 0.60 (Table 2). A similar model with release year-day in place of time lag was less supported ( $\overline{\text { RWMSE }}=$ 0.0047 and $\overline{\mathrm{R}_{\mathrm{CV}}^{2}}=0.45$ ), but including either measure of release timing was better than including none at all $\left(\overline{\mathrm{RWMSE}}=0.0051\right.$ and $\left.\overline{\mathrm{R}_{\mathrm{CV}}^{2}}=0.41\right)$.

The earliest releases appeared to survive poorly (Fig. 3a,b), and releases approximately $90 \mathrm{~d}$ after the spring transition appeared to do better than even later releases (Fig. 3a). Very late releases may have also fared well (Fig. 3a,b), but there were few data points driving this part of the curve and most points were from early release years. Releases of heavier 
1981

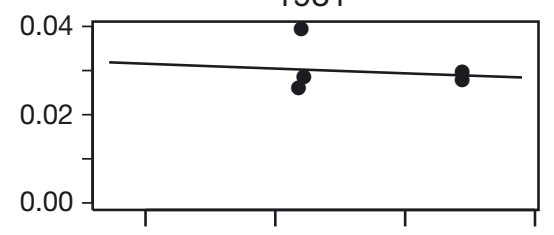

1985
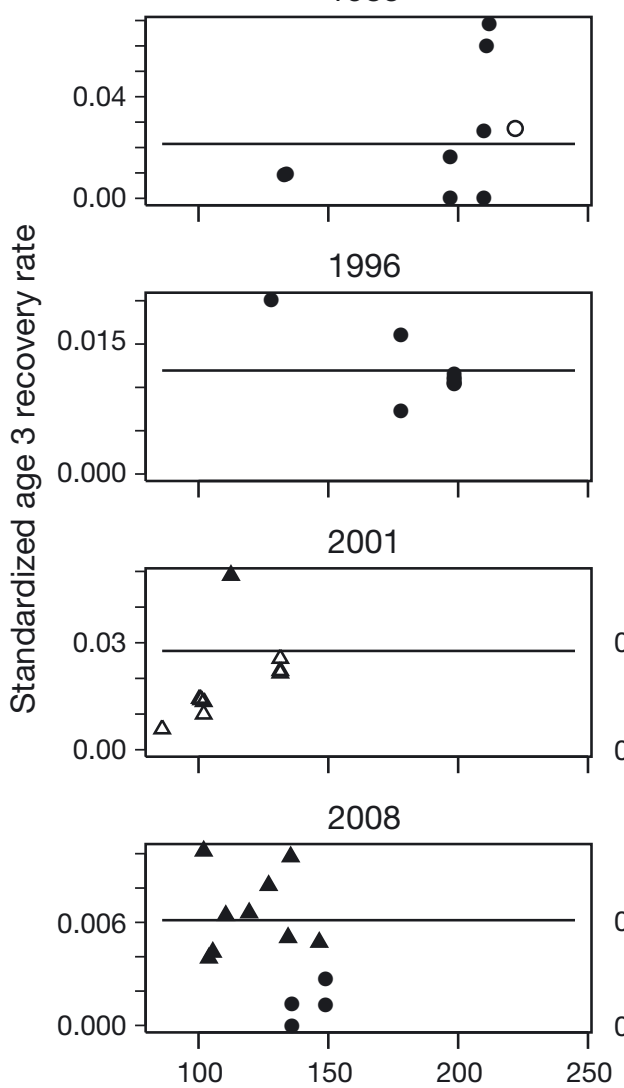

1982

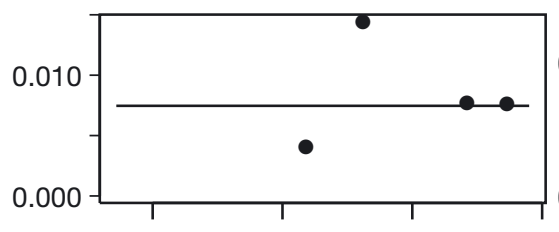

1986

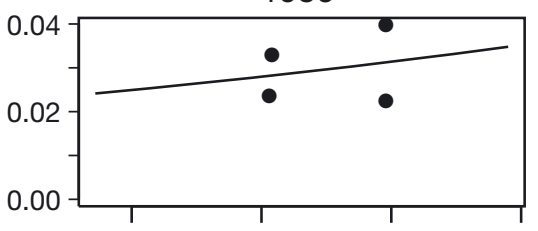

1999
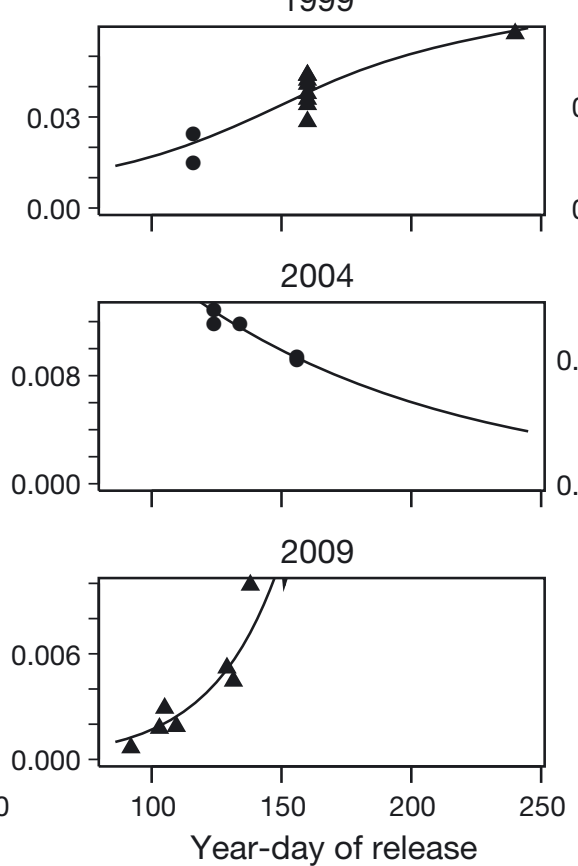

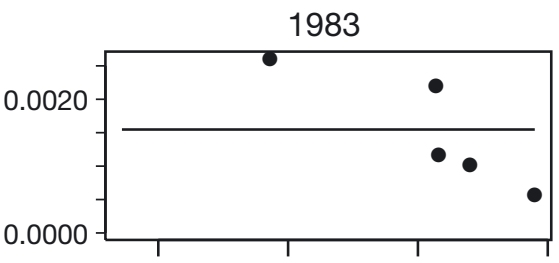

1994

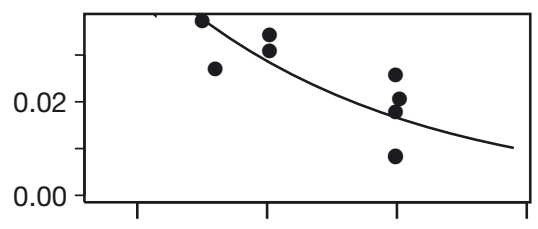

2000
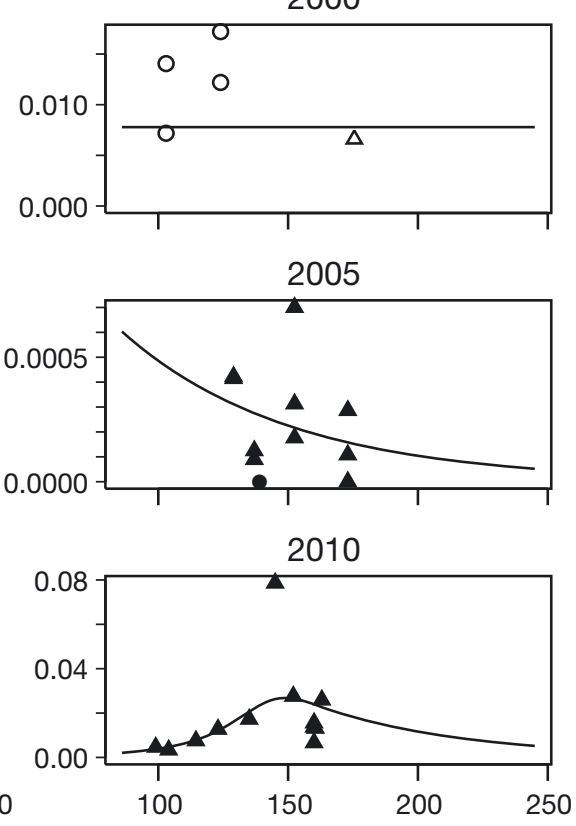

Fig. 2. Age 3 ocean recovery rates standardized by SRFC harvest rates as a function of release date (year-day) for Feather River Hatchery releases. Releases spanning $>30 \mathrm{~d}$ were excluded, as were release groups with missing weight information and those released as smolts or fry. Open symbols denote mention of disease or poor condition, and triangles denote releases that were acclimated in net-pens. Filled circles are fish that were not diseased and not acclimated in pens. Fitted lines are intercept-only or GAM models chosen based on leave-one-out cross validation and minimum root weighted mean squared error

(RWMSE). Note that $y$-axis scales vary among panels

fish had higher survival rates (Fig. 3c), and fish with disease were less likely to survive (Fig. 3d). Fish acclimated in net pens may have had poorer survival but not significantly so (Fig. 3e). Even after accounting for these effects, there was substantial variation in estimated year effects on recovery (Fig. 4).

\section{DISCUSSION}

The overall goal of this study was to investigate the importance of ocean arrival timing on salmon sur- vival to test the hypothesis that timing relative to ecosystem phenology would influence salmon ocean survival. We found support for the importance of arrival timing relative to spring transition to driving intra-annual variation in salmon survival (i.e. our 'Time lag' model received the strongest support; Table 2), but we also found an effect of calendar date irrespective of ocean phenology (i.e. our 'Year-Day' model received more support than a model without any time effect; Table 2).

The use of model comparison techniques and GAMs allowing for nonlinear relationships provided 
Table 2. Results of model comparison analyzing Feather River Hatchery releases for release years 1981 to 2010. Top models with the lowest mean prediction errors (ranked by $\overline{\mathrm{RWMSE}}$ ) and their associated mean cross validation $\mathrm{R}^{2}$ values $\left(\overline{R_{C V}^{2}}\right)$ are shown. $\left({ }^{*}\right)$ indicates a particular term was included in the model $_{i}(-)$ indicates it was excluded. $v$ : maximum degrees of freedom, with $\infty$ denoting unconstrained degrees of freedom

\begin{tabular}{|c|c|c|c|c|c|c|}
\hline Year & Weight & Time, v & Net pen & Disease & $\overline{\mathrm{RWMSE}}$ & $\overline{\mathrm{R}_{\mathrm{CV}}^{2}}$ \\
\hline * & * & Lag, 4 & * & * & 0.00367 & 60.1 \\
\hline * & $*$ & Lag, 5 & * & * & 0.00370 & 59.7 \\
\hline * & $*$ & $\operatorname{Lag}_{,} \infty$ & * & * & 0.00370 & 60.1 \\
\hline * & * & $\mathrm{Lag}_{1} 4$ & - & * & 0.00371 & 59.8 \\
\hline * & - & Lag, 4 & * & * & 0.00372 & 59.0 \\
\hline * & - & Lag, 5 & * & $*$ & 0.00373 & 59.0 \\
\hline * & - & $\operatorname{Lag}_{,} \infty$ & * & * & 0.00373 & 59.4 \\
\hline * & * & Year-day, 3 & - & * & 0.00471 & 44.8 \\
\hline * & $*$ & Year-day, 3 & $*$ & $*$ & 0.00475 & 44.6 \\
\hline * & - & - & - & * & 0.00505 & 41.3 \\
\hline
\end{tabular}

strong support for a relationship between ocean entry timing and survival, inferred by recovery rates in ocean fisheries standardized by SRFC harvest rates. At the same time, we note very strong year effects (i.e. controlling for modeled effects of release time and other covariates such as fish size) on survival rates irrespective of timing. For example, the central $90 \%$ of year effects corresponded to predicted age 3 survival rates that varied 19-fold according to the best-supported model applied to the full dataset (Fig. 4a). Note that this period excluded 2 years of very low recovery rates corresponding to the recent salmon collapse and fishery closure
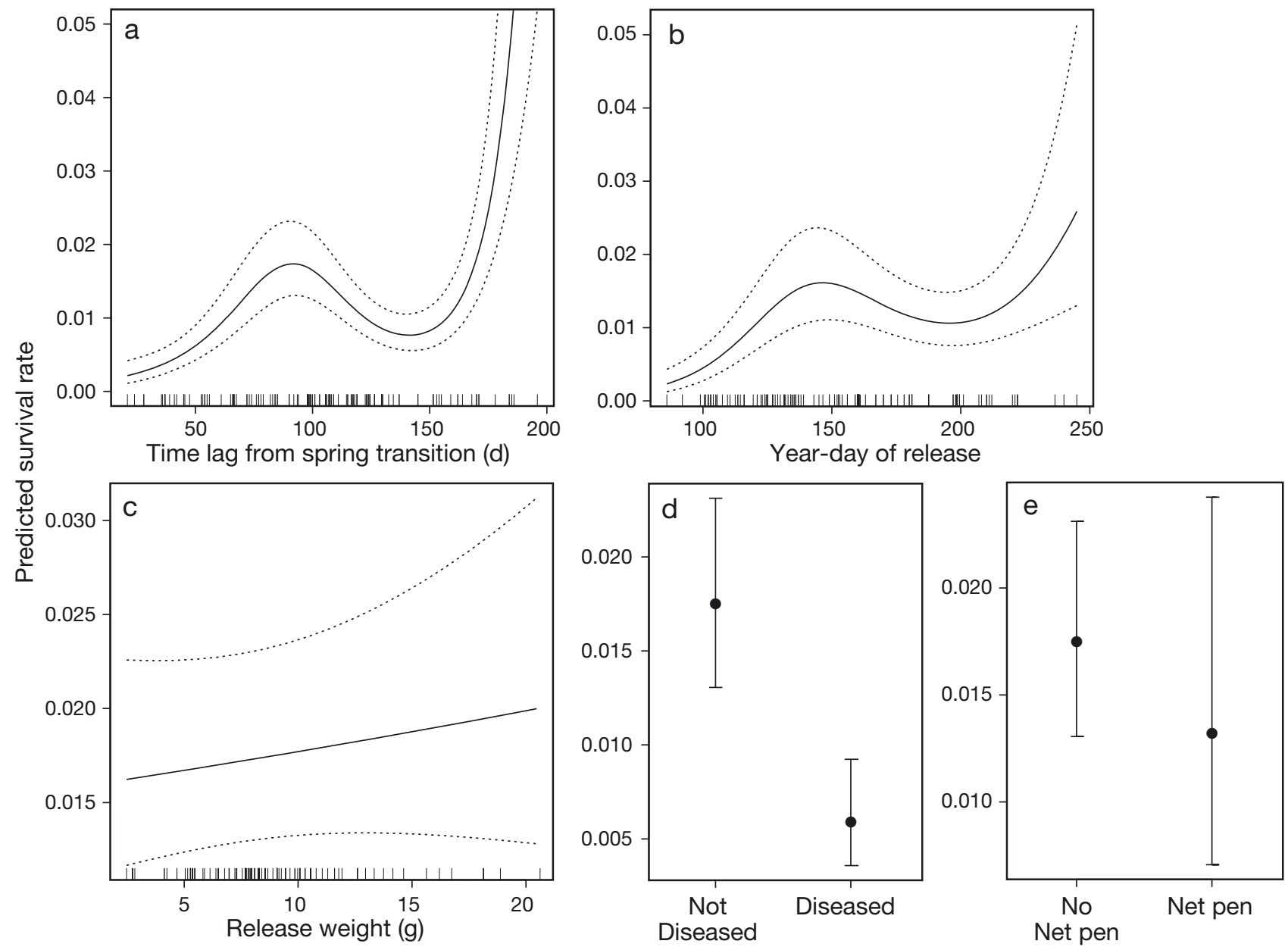

Fig. 3. Model predicted survival rate (harvest-adjusted recovery rates with approximate $95 \%$ predictive intervals) illustrating the fitted effects of timing measured as (a) time lag from spring transition, (b) timing measured as year-day, (c) release weight, (d) the presence of disease, and (e) the use of net pens. Predictions are for the year with median fitted year effect (1996), and at the optimal time lag of 92 days (all but a and b), median release weight (all but c), without disease (all but d), or without net pen (all but e). The rug-plots represent values of the independent variable with associated data 

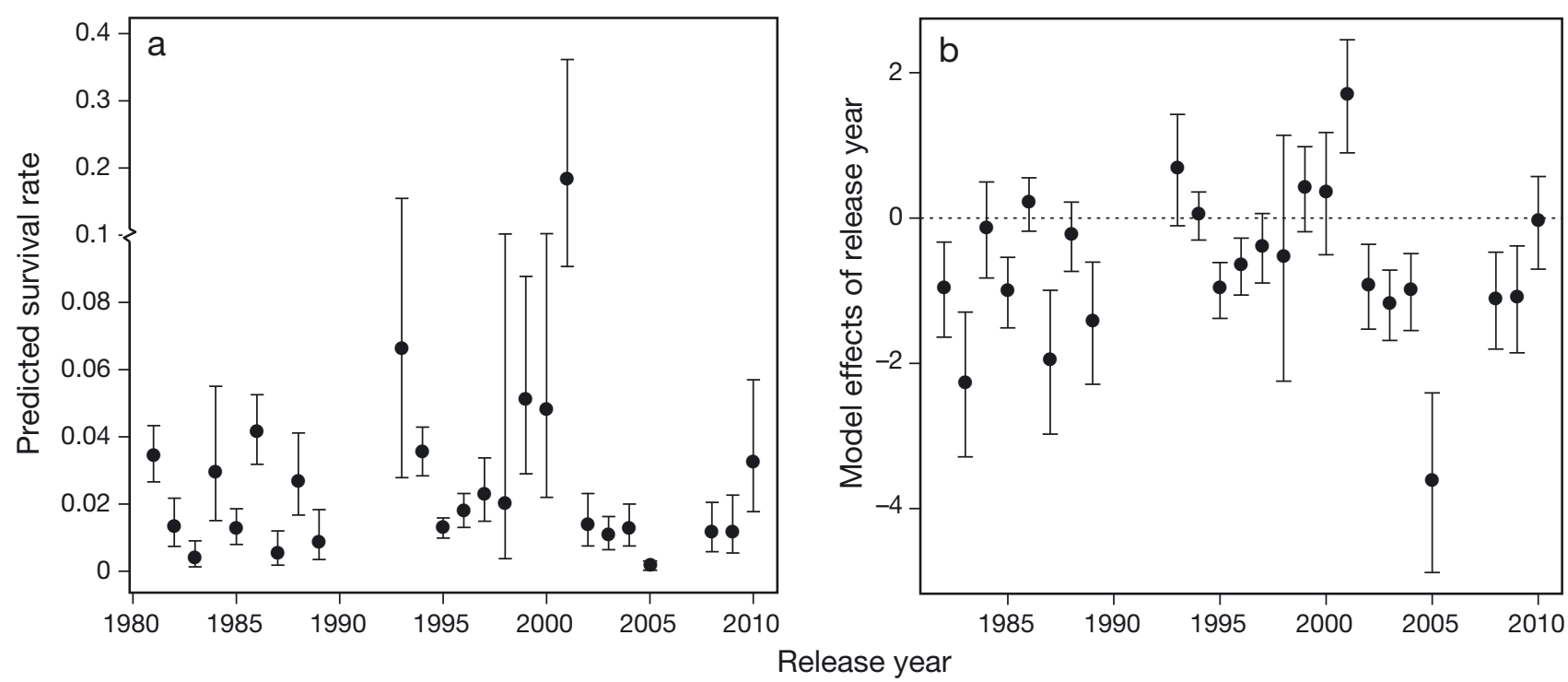

Fig. 4. Fitted year effects in the best-supported model, presented as (a) predicted harvest-adjusted recovery rates (with approximate $95 \%$ prediction intervals) given release of non-diseased, non-net pen, median-weight fish at the optimal time lag from the spring transition date (92 d). Also presented are (b) model year effects (with approximate $95 \%$ prediction intervals) on the log scale

(Lindley et al. 2009), so overall variation in year effects may be even greater.

The degree of variation in year effects is not surprising given the numerous ecological factors acting at longer time scales that may affect early ocean survival - for example, important effects of upwelling intensity, mixing, mesoscale activity, and advection are apparent in this system (Santora et al. 2011, 2012, in press, Ralston et al. 2013), as are preconditioning effects carried over from the previous year (Schroeder et al. 2009, 2013). For instance, the most extreme year effect is associated with release year 2005 and is highly negative (Fig. 4b); while the timing of spring transition was earlier than average in 2005, upwelling that followed was particularly weak (Lindley et al. 2009). This year was also characterized by anomalous poleward transport during the winter 2005 and low krill survival in spring (Dorman et al. 2011). Apparent year effects on age 3 recovery may also reflect temporal variation in age 2 maturation, natural mortality, and/or exploitation, but we do not attempt to model age 2 dynamics due to limited data, as described in Supplement 1.

While our results provide strong support for the existence of a nonlinear relationship between release timing and survival rates within years, there is some ambiguity regarding the explanatory power of timing per se (i.e. year-day) versus timing relative to characteristics of ecosystem phenology (here, using the spring transition date as a metric of phenology).
In addition, effects of release time on survival rates are not fully consistent across years (see Fig. 2; variation among years was also reported by Scheuerell et al. 2009). Indeed, previous studies have reported effects of smolt size or early growth rates on marine survival in some years but not others (in particular, size or growth rate may only be strong predictors in stressful years: Holtby et al. 1990, Tomaro et al. 2012, Woodson et al. 2013), so it is not surprising that relationships between release timing and survival may vary across years as well. Thus, variable timing of ocean entry may amount to little more than making the most of a bad situation in some years.

Further, the apparent effects of timing and release weight are complicated by the collinearity between release time and fish size, although with $\mathrm{r}=0.50$, the observed correlation in the analyzed dataset is below the threshold often invoked as problematic (Dormann et al. 2013). In this case, our results suggested poor survival of either very early releases or releases of small fish, which tend to occur together. Teasing apart the relative influence of timing and size is challenging because these traits are often correlated. However, in a series of experimental releases designed to test the relative importance of timing versus size, Bilton et al. (1984) and Morley (1988) reported stronger effects of timing than size on survival of coho salmon and Whitman (1987) found similar results for Chinook salmon. 
Even using cross validation methods, the very large apparent sample sizes made possible by multiple CWT release groups can easily lead to overfitting if the assumption of statistical independence is violated, making it difficult to unambiguously identify the most important predictors of survival or rigorously quantify their effects. An additional concern is the leverage of extreme values when our dataset contains only a few late releases from early years. Finally, the unbalanced design is a concern, both in terms of potentially conflating year effects with covariates unequally distributed among years and differential influence on overall model results of years with different sample sizes and temporal spread of releases. Unfortunately, uncertainty and sensitivity to model specification and choice of dataset is an unavoidable consequence of using ocean recovery rates to infer survival, a problem affecting this and other studies with important management implications. We are attempting to address a complicated problem with data collected by a fishery, not a planned sampling scheme executed in the context of a designed experiment. Thus, we did not attempt to fit even more complicated models including year-bytiming interactions or additional environmental covariates.

Nevertheless, despite the presence of numerous confounding factors we did not attempt to model directly, we found evidence for a relationship between ocean entry or hatchery release timing and survival rates that was strong enough for a clear signal to emerge for the average effect. In addition, there appeared to be an optimal time after accounting for other effects such as body size, with some suggestion that this optimal timing within a given year could be predicted relative to the spring transition date. A similar analysis by Ryding \& Skalski (1999) also supported optimal conditions for early marine survival of coho salmon related to the date of spring transition. Even though the predicted effects of small changes in release timing are generally small, given very large total releases (average 32 million $\mathrm{yr}^{-1}$ from 2000 to 2010 across all 5 hatcheries; E. Huber \& S. Carlson unpubl.), a small change in survival may still translate into a large number of returning adult fish. Of course, regardless of release timing, we expect reduced survival overall in years of generally poor ocean conditions (e.g. Barth et al. 2007, Lindley et al. 2009).

Translating these results into advice on hatchery practices may prove difficult for several reasons. For example, the effects of timing described here were generally small aside from poor survival of the earli- est releases and the apparent but uncertain increase in survival of the very late releases (Fig. 3a,b). Specifically, survival rates increase 2.3-fold when time lag decreases from the local minimum of $149 \mathrm{~d}$ to the local maximum of $92 \mathrm{~d}$, compared to a 19-fold difference in survival due to year effects. Beyond a weak effect of timing, the 'peaks' corresponding to optima were generally broad. Moreover, spring transition date is variable from year to year (Fig. 1) and may not be known far enough in advance to alter hatchery conditions such that fish will be prepared for release at a target time. Further, we found significant effects of fish size, which is difficult if not impossible to manipulate independently of release time (i.e. releasing fish at a later date often involves releasing them at a larger size).

In addition, our results suggest that the relationship between relative survival and release timing does not always show a consistent within-year pattern (Fig. 2), and this variability combined with a lack of prior knowledge of spring transition timing might argue for staggered release times. Such staggering might be accomplished through direct staggering of release timings by hatchery managers or by increased on-site releases, as has been advocated recently for other reasons (California Hatchery Scientific Review Group 2012). Indeed, different release strategies among hatcheries could contribute relevant variation to the portfolio effect in this system, akin to stock or run-specific variation typical of less-impacted systems (Hilborn et al. 2003). On-site releases would also tend to lead to staggered ocean entry timing as fish made their individual paths down the river, although on-site releases do face added mortality risks in rivers. Williams (2006, his Fig. 5-28) notes that Chinook believed to be fall or spring run are recovered in San Francisco Bay all year, but recoveries peak in April or May and are very low before February or after July (consistent with the full distribution of Feather River Hatchery release dates analyzed but wider than a typical single year; Fig. S1 in the Supplement). In addition, fish migrating downstream may be able to adjust their transit time in response to environmental cues, possibly allowing fish to arrive during more favorable conditions.

Acknowledgements. This work was supported by funding from California Sea Grant (R/FISH-217) and the California Sea Grant Ocean Protection Council. We thank A. Grover, D. Hankin, M. Mohr, M. O'Farrell, and I. Schroeder for helpful discussions and assistance with accessing data and O. Shelton and A. Winhip for helpful comments on earlier drafts of the manuscript. 


\section{LITERATURE CITED}

Barth JA, Menge BA, Lubchenco J, Chan F and others (2007) Delayed upwelling alters nearshore coastal ocean ecosystems in the northern California Current. Proc Natl Acad Sci USA 104:3719-3724

Beverton RJH, Holt SJ (1957) On the dynamics of exploited fish populations. Fishery Investigations Ser II Vol XIX. Ministry of Agriculture, Fisheries and Food, London

> Bilton HT, Alderdice DF, Schnute JT (1982) Influence of time at release of juvenile coho salmon (Oncorhynchus kisutch) on returns at maturity. J Fish Res Board Can 39: 426-447

Bilton HT, Morley RB, Coburn AS, van Tyne J (1984) The influence of time and size at release of juvenile coho salmon (Oncorhynchus kisutch) on returns at maturity; results from releases from Quinsan River Hatchery, B.C., in 1980. Fisheries and Oceans Canada, Nanaimo, BC

Bograd SJ, Schroeder I, Sarkar N, Qiu X, Sydeman WJ, Schwing FB (2009) Phenology of coastal upwelling in the California Current. Geophys Res Lett 36:L01602, doi:10. 1029/2008GL035933

> Budy P, Thiede G, Bouwes N, Petrosky CE, Schaller H (2002) Evidence linking delayed mortality of Snake River salmon to their earlier hydrosystem experience. N Am J Fish Manag 22:35-51

Burke BJ, Peterson WT, Beckman BR, Morgan C, Daly EA, Litz M (2013) Multivariate models of adult Pacific salmon returns. PLoS ONE 8:e54134

California Hatchery Scientific Review Group (2012) California Hatchery Review Report. Prepared for the US Fish and Wildlife Service and Pacific States Marine Fisheries Commission, CA

Croll DA, Marinovic B, Benson S, Chavez FP, Black N, Ternullo R, Tershy BR (2005) From wind to whales: trophic links in a coastal upwelling system. Mar Ecol Prog Ser 289:117-130

> Cushing DH (1990) Plankton production and year-class strength in fish populations: an update of the match/ mismatch hypothesis. Adv Mar Biol 26:249-293

> Deriso RB, Maunder MN, Pearson WH (2008) Incorporating covariates into fisheries stock assessment models with application to Pacific herring. Ecol Appl 18:1270-1286

Dorman JG, Powell TM, Sydeman WJ, Bograd SJ (2011) Advection and starvation cause krill (Euphausia pacifica) decreases in 2005 Northern California coastal populations: implications from a model study. Geophys Res Lett 38:L04605, doi:10.1029/2010GL046245

> Dormann CF, Elith J, Bacher S, Buchmann C and others (2013) Collinearity: a review of methods to deal with it and a simulation study evaluating their performance. Ecography 36:27-46

> Graham WW, Largier JL (1997) Upwelling shadows as nearshore retention sites: the example of northern Monterey Bay. Cont Shelf Res 17:509-532

Hankin DG (1990) Effects of month of release of hatcheryreared Chinook salmon on size at age, maturation schedule, and fishery contribution. Info Rep Number 90-4. Oregon Department of Fish and Wildlife, Portland, OR

> Hilborn R, Quinn TP, Schindler DE, Rogers DE (2003) Biocomplexity and fisheries sustainability. Proc Natl Acad Sci USA 100:6564-6568

Hjort J (1914) Fluctuations in the great fisheries of northern Europe, viewed in the light of biological research. Rapp P-V Reun Cons Int Explor Mer 20:1-228
Holtby LB, Andersen BC, Kadowaki RK (1990) Importance of smolt size and early ocean growth to interannual variability in marine survival of coho salmon (Oncorhynchus kisutch). Can J Fish Aquat Sci 47:2181-2194

> Jacobson LD, MacCall AD (1995) Stock-recruitment models for Pacific sardine (Sardinops sagax). Can J Fish Aquat Sci 52:566-577

Johnson JK (1990) Regional overview of coded wire tagging of anadromous salmon and steelhead in northwest America. Am Fish Soc Symp 7:782-816

Lapi L, Hamer M, Johnson B (1990) Data organization and coding for a coastwide mark-recovery data system. Am Fish Soc Symp 7:720-724

Lindley ST, Grimes CB, Mohr MS, Peterson W and others (2009) What caused the Sacramento River fall Chinook stock collapse? NOAA Tech Memo NOAA-TM-NMFSSWFSC-447

- Logerwell EA, Mantua N, Lawson PW, Francis RC, Agostini VN (2003) Tracking environmental processes in the coastal zone for understanding and predicting Oregon coho (Oncorhynchus kisutch) marine survival. Fish Oceanogr 12:554-568

McGurk MD (1996) Allometry of marine mortality of Pacific salmon. Fish Bull 94:77-88

Morley RB (1988) The influence of time and size at release of juvenile coho salmon (Oncorhynchus kisutch) on returns at maturity: results of studies on three brood years at Quinsam Hatchery, B.C. Can Tech Rep Fish Aquat Sci 1620

> Myers RA (1998) When do environment-recruitment correlations work? Rev Fish Biol Fish 8:285-305

Nandor GF, Longwill JR, Webb DL (2010) Overview of the coded wire tag program in the greater Pacific region of North America. In: Wolf KS, O'Neal JS (eds) PNAMP Special Publication: tagging, telemetry and marking measures for monitoring fish populations - A compendium of new and recent science for use in informing technique and decision modalities. Pacific Northwest Aquatic Monitoring Partnership, Duvall, WA, p 5-46

O'Farrell MR, Mohr MS, Palmer-Zwahlen ML, Grover AM (2013) The Sacramento Index (SI). NOAA Tech Memo NOAA-TM-NMFS-SWFSC-512

> Petrosky CE, Schaller HA (2010) Influence of river conditions during seaward migration and ocean conditions on survival rates of Snake River Chinook salmon and steelhead. Ecol Freshw Fish 19:520-536

Quinn TP (2005) The behavior and ecology of Pacific salmon and trout. American Fisheries Society and University of Washington, Seattle, WA

Quinn TJ, Deriso RB (1999) Quantitative fish dynamics. Oxford University Press, New York, NY

R Development Core Team (2012) R: a language and environment for statistical computing. R Foundation for Statistical Computing, Vienna

> Raff MS (1956) On approximating the point binomial. J Am Stat Assoc 51:293-303

Ralston S, Field JC, Sakuma K (2013) Interannual variation in pelagic juvenile rockfish abundance-going with the flow. Fish Oceanogr 22:288-308

$>$ Raymond HL (1979) Effects of dams and impoundments on migrations of juvenile chinook salmon and steelhead from the Snake River, 1966 to 1975. Trans Am Fish Soc 108:505-529

Raymond HL (1988) Effects of hydroelectric development and fisheries enhancement on spring and summer chi- 
nook salmon and steelhead in the Columbia River Basin. N Am J Fish Manag 8:1-24

> Rechisky EL, Welch DW, Porter AD, Jacobs-Scott MC, Winchell PM, McKern JL (2012) Estuarine and early-marine survival of transported and in-river migrant Snake River spring Chinook salmon smolts. Sci Rep 2:448

Rupp DE, Wainwright TC, Lawson PW, Peterson WT (2012) Marine environment-based forecasting of coho salmon (Oncorhynchus kisutch) adult recruitment. Fish Oceanogr 21:1-19

Ryding KE, Skalski JR (1999) Multivariate regression relationships between ocean conditions and early marine survival of coho salmon (Oncorhynchus kisutch). Can J Fish Aquat Sci 56:2374-2384

Santora JA, Sydeman WJ, Schroeder ID, Wells BK, Field JC (2011) Mesoscale structure and oceanographic determinants of krill hotspots in the California Current: implications for trophic transfer and conservation. Prog Oceanogr 91:397-409

Santora JA, Field JC, Schroeder ID, Sakuma KM, Wells BK, Sydeman WJ (2012) Spatial ecology of krill, micronekton and top predators in the central California Current: implications for defining ecologically important areas. Prog Oceanogr 106:154-174

Santora JA, Schroeder ID, Field JC, Wells BK, Sydeman WJ (in press) Spatio-temporal dynamics of ocean conditions and forage taxa reveals regional structuring of seabirdprey relationships. Ecol Appl, doi:10.1890/13-1605.1

Satterthwaite WH, Mohr MS, O'Farrell MR, Anderson EC and others (2014) Use of genetic stock identification data for comparison of the ocean spatial distribution, size-atage, and fishery exposure of an untagged stock and its indicator: Klamath River versus California Coastal Chinook salmon. Trans Am Fish Soc 143:117-133

Scheuerell MD, Zabel RW, Sandford BP (2009) Relating juvenile migration timing and survival to adulthood in two species of threatened Pacific salmon (Oncorhynchus spp.). J Appl Ecol 46:983-990

Schroeder ID, Sydeman WJ, Sarkar N, Thompson SA, Bograd SJ, Schwing FB (2009) Winter pre-conditioning of seabird phenology in the California Current. Mar Ecol Prog Ser 393:211-223

Schroeder ID, Black BA, Sydeman WJ, Bograd SJ, Hazen EL, Santora JA, Wells BK (2013) The North Pacific High and wintertime pre-conditioning of California Current productivity. Geophys Res Lett 40:541-546

Schwing FB, Bond NA, Bograd SJ, Mitchell T, Alexander MA, Mantua N (2006) Delayed coastal upwelling along the US West Coast in 2005: a historical perspective. Geophys Res Lett 33:L22SO1, doi:10.1029/2006GL026911

Shao J (1993) Linear model selection by cross-validation. J Am Stat Assoc 88:486-494

> Thompson SS, Sydeman WJ, Santora JA, Black BA and others (2012) Linking predators to seasonality of upwelling: using food web indicators and path analysis to infer

Editorial responsibility: Konstantinos Stergiou, Thessaloniki, Greece trophic connections. Prog Oceanogr 101:106-120

> Tomaro LM, Teel DJ, Peterson WT, Miller JA (2012) When is bigger better? Early marine residence of middle and upper Columbia River spring Chinook salmon. Mar Ecol Prog Ser 452:237-252

Ver Hoef JM, Boveng P (2007) Quasi-Poisson vs. negative binomial regression: How should we model overdispersed count data? Ecology 88:2766-2772

Ward BR, Slaney PA, Facchin AR, Land RW (1989) Sizebiased survival in steelhead trout (Oncorhynchus mykiss): back-calculated lengths from adults' scales compared to migrating smolts at the Keogh River, British Columbia. Can J Fish Aquat Sci 46:1853-1858

> Weitkamp L, Neely K (2002) Coho salmon (Oncorhynchus kisutch) ocean migration patterns: insight from marine coded-wire tag recoveries. Can J Fish Aquat Sci 59: 1100-1115

> Wells BK, Grimes CB, Waldvogel JB (2007) Quantifying the effects of wind, upwelling, curl, sea surface temperature and sea level height on growth and maturation of a California Chinook salmon (Oncorhynchus tshawytscha) population. Fish Oceanogr 16:363-382

> Wells BK, Field JC, Thayer JA, Grimes CB and others (2008) Untangling the relationships among climate, prey and top predators in an ocean ecosystem. Mar Ecol Prog Ser 364:15-29

- Wells BK, Santora JA, Field JC, MacFarlane RB, Marinovic BB, Sydeman WJ (2012) Population dynamics of Chinook salmon Oncorhynchus tshawytscha relative to prey availability in the central California coastal region. Mar Ecol Prog Ser 457:125-137

Whitman RP (1987) An analysis of smoltification indices in fall chinook salmon (Oncorhynchus tshawytscha). MS thesis, University of Washington, Seattle, WA

Williams JG (2006) Central Valley salmon: a perspective on Chinook and steelhead in the Central Valley of California. San Francisco Estuar Watershed Sci 4:1-398

> Williams JG (2008) Mitigating the effects of high-head dams on the Columbia River, USA: experience from the trenches. Hydrobiologia 609:241-251

Wing SR, Botsford LW, Ralston SV, Largier JL (1998) Meroplanktonic distribution and circulation in a coastal retention zone of the northern California upwelling system. Limnol Oceanogr 43:1710-1721

> Wood SN (2011) Fast stable restricted maximum likelihood and marginal likelihood estimation of semiparametric generalized linear models. J R Stat Soc B 73:3-36

- Woodson L, Wells BK, Johnson RC, Weber P, MacFarlane RB, Whitman G (2013) Size, growth, and origin-dependent mortality of juvenile Chinook salmon Oncorhynchus tshawytscha during early ocean residence. Mar Ecol Prog Ser 487:163-175

$>$ Zabel RW, Williams JG (2002) Selective mortality in Chinook salmon: What is the role of human disturbance? Ecol Appl 12:173-183

Submitted: January 13, 2014; Accepted: July 1, 2014

Proofs received from author(s): September 15, 2014 